Pacific Journal of Mathematics

ON THE SPECTRAL RADIUS OF HERMITIAN ELEMENTS IN 


\section{ON THE SPECTRAL RADIUS OF HERMITIAN ELEMENTS IN GROUP ALGEBRAS}

\section{A. HULANICKI}

Let $G$ be a discrete group and $\mathfrak{U}$ the $L_{1}$ algebra over the field of complex numbers of $G$. The aim of the paper is to consider some combinatorial conditions on the group $G$ which imply symmetry of the algebra $\mathfrak{A}$. One result is as follows:

If a group $F$ contains a subgroup $G$ of finite index such that any element of $G$ has finitely many conjugates, then the group algebra $\mathfrak{A}$ of $F$ is symmetric.

A Banach *-algebra $\mathfrak{A}$ is said to be symmetric if for every element $x \in \mathfrak{A}$ the spectrum of the element $x^{*} x$ is real and nonnegative. If the algebra $\mathfrak{U}$ contains the unit element, this can be equivalently stated as

For every linear functional $F$ on $\mathfrak{A}$

$$
F\left(y+y x^{*} x\right)=0 \text { for every } y \in \mathfrak{A} \text { implies } F=0 .
$$

It is well known and easy to prove that the group algebra of a finite or Abelian locally compact group is symmetric. If a discrete group is neither finite nor Abelian, all that is known about symmetry of its group algebra seems to be due to Bonic [2].

Bonic proved the following facts:

(i) The group algebra of the direct product of two groups one of which is Abelian, the other of which has a symmetric group algebra is symmetric.

(ii) The group algebra of a splitting extension of an Abelian group by the cyclic group of two elements is symmetric.

(iii) The group algebra of a free nonAbelian group is not symmetric.

(i) and (ii) together with the fact that the group algebras of finite and Abelian groups are symmetric establishes the scope of groups about which, using Bonic's results, one may assert symmetry. As a matter of fact, it is not more than the direct products of finitely many finite, Abelian and dihedral-type groups. The method applied by Bonic is based on (1), which in the case of group algebra of a discrete group is equivalent to the implication

(2) If $f$ is bounded and $f(t)+\sum_{s \in G} x^{*} x\left(s^{-1} t\right) f(s) \equiv 0$, then $f \equiv 0$. 
It is not surprising that, if some of the elements of the group appear as complicated expressions of the generators, then to prove or disprove (2) may become difficult.

We propose another approach to this circle of problems.

Our starting point is a theorem of Raikov, cf. [9], [10]. Denote by $\nu(x)$ the spectral radius of an element $x$ in a Banach *-algebra $\mathfrak{A}$, that is, let

$$
\nu(x)=\lim _{n \rightarrow \infty}\left\|x^{n}\right\|^{1 / n} .
$$

For any *-representation $x \rightarrow T_{x}$ of $\mathfrak{X}$ we have

$$
\nu\left(x^{*} x\right) \geqq\left\|T_{x * x}\right\|,
$$

cf. e.g. [11]. Raikov's theorem says:

A Banach *-algebra $\mathfrak{A}$ is symmetric if, and only if,

$$
\nu\left(x^{*} x\right)=\sup \left\|T_{x^{*} x}\right\|
$$

where the least upper bound on the right hand side is taken over all *-representations of $\mathfrak{A}$.

Now let $\mathfrak{A}$ be a group algebra $\mathfrak{A}=\mathfrak{A}(G)$ of a discrete group $G$ with the usual norm, multiplication, and involution

$$
\|x\|=\sum_{s \in G}|x(s)|, x * y(s)=\sum_{t \in G} x(t) y\left(t^{-1} s\right), x \sim(s)=\overline{x\left(s^{-1}\right)},
$$

respectively. Consider the left regular representation $T$ of $\mathfrak{A}(G) x \rightarrow$ $T_{x}$, where the Hilbert space of $T$ is $L_{2}(G)$ equipped with norm

$$
\|x\|_{2}=\left(\sum_{s \in G}|x(s)|^{2}\right)^{1 / 2} \text { and } T_{x} f=x * f, f \in L_{2}(G) .
$$

Denote

$$
\lambda(x)=\left\|T_{x}\right\| \text {. }
$$

It may happen (cf. [7]) that the left regular representation weakly contains (cf. [3]) all *-representation of $\mathfrak{A}(G)$, which is to say that $\lambda\left(x^{\sim} * x\right) \geqq\left\|T_{x_{* * x}}^{\prime}\right\|$ for any *-representation $T^{\prime}$ of $\mathfrak{2}(G)$. Then (3) turns into the equality

$$
\lambda\left(x^{\sim} * x\right)=\nu\left(x^{\sim} * x\right) .
$$

Our aim is to find sufficient conditions on a group $G$ which imply (4) for any element $x$ of its group algebra $\mathfrak{A}(G)$, and consequently the symmetry of $\mathfrak{A}(G)$. We formulate the conditions in the forthcoming $\S 1$ and we devote $\S 2$ to the proof that, in fact, they imply (4). Finally, in $\S 3$, we discuss the classes of groups for which our conditions are satisfied. 
The author is most indebted to Professor B. H. Neumann for a conversation about these classes of groups as well as to Dr. Neil W. Rickert who suggested several corrections and simplifications.

1. Let $G$ be a discrete group, $\mathfrak{A}=\mathfrak{A}(G)$ its group algebra. For any function $x$ on $G$ we denote by $N(x)$ the support of the function $x$, i.e.,

$$
N(x)=\{s: x(s) \neq 0\} .
$$

Let $A_{1}, \cdots, A_{n}$ be a family of subset of $G$. By $A_{1} \cdots A_{n}$ we denote the set of all products $a_{1} \cdots a_{n}$, where $a_{i} \in A_{i}, i=1, \cdots, n$. We shall also use the abbreviated notation $A^{n}$ for $A \cdots A$. For a finite subset $A$ of $G$ we denote by $|A|$ the number of the elements of $A$. Clearly,

$$
\left|A_{1} \cdots A_{n}\right| \leqq\left|A_{1}\right| \cdots\left|A_{n}\right| \text {. }
$$

For any two nonnegative integers $m \leqq n$ we denote by $t(m, n)$ a sequence

$$
t(m, n)=\left\langle t_{1}, \cdots, t_{n}\right\rangle
$$

of elements of $G$ such that at most $m$ of the $t_{i}^{\prime} s, i=1, \cdots, n$, are different from the unity of $G$. We say that a group $G$ satisfies condition $(\mathrm{C})$ if

(C) There exists a constant $k$ such that for any finite set $A \subset G$ there exists a constant $C=C(A, c)$ such that for any sequence $\left\langle t_{1}, \cdots, t_{n}\right\rangle=t(m, n)$

$$
\left|A t_{1} A t_{2} \cdots A t_{n}\right| \leqq C k^{m} c^{n} \text { for any } c>1 \text {. }
$$

For $m=0$ (or, which is the same, for bounded $m$ ) condition (C) turns into the following one:

$(A-S)$ For any finite subset $A$ of $G$

$$
\left|A^{n}\right|=o\left(c^{n}\right) \text { for any } c>1 \text {. }
$$

This condition has been considered by G. M. Adel'son-Vel'skiǐ and Yu. A. Sreider in [1]. They have proved that $(A-S)$ implies the existence of an invariant Banach mean value on $G$. Clearly, $(\mathrm{A}-\mathrm{S})$ implies the Folner conditions cf. [4].

2. First we formulate two simple lemmas.

LEMma 1. If $G$ is a (discrete) group, then for any $x \in \mathfrak{A}(G) \subset L_{2}(G)$, we have $\lambda(x) \geqq\|x\|_{2}$. 
In fact,

$$
\lambda(x)=\sup _{\|y\|_{2}=1}\|x * y\|_{2} \geqq\|x * \delta\|_{2}=\|x\|_{2}
$$

where $\delta$, the unit element of $\mathfrak{U}(G)$, is the function which takes value 1 at the unity of $G$ and zero elsewhere.

LEMMA 2. If $x_{1}, \cdots, x_{n} \in \mathfrak{A}(G)$, then

(i ) $x_{1} * \cdots * x_{n}(s)=\sum_{t_{1}, \cdots, t_{n} \in G} x_{1}\left(t_{1}\right) \cdots x_{n}\left(t_{n}\right) \delta\left(t_{n}^{-1} \cdots t_{1}^{-1} s\right)$

(ii) $N\left(x_{1} * \cdots * x_{n}\right) \leqq N\left(x_{1}\right) \cdots N\left(x_{n}\right)$

(iii) $N\left(x^{\sim}\right)=(N(x))^{-1}=\left\{t^{-1}: t \in N(x)\right\}$.

The proof of (i) is obtained by an elementary induction. To verify (ii) we simply note that, by (i), $s \in N\left(x_{1} * \cdots * x_{n}\right)$ implies

$$
t_{n-1}^{-1} \cdots t_{1}^{-1} s=t_{n} \in N\left(x_{n}\right) \text { and } t_{i} \in N\left(x_{i}\right), i=1, \cdots, n \text {. }
$$

Therefore $s=t_{1} \cdots t_{n} \in N\left(x_{1}\right) \cdots N\left(x_{n}\right)$.

From now on we shall frequently use the abbreviated notation $x^{* n}$ for $x * \cdots * x$.

THEOREM 1. If a group $G$ satisfies $(\mathrm{A}-\mathrm{S})$, then for every $x$ such that $N(x)$ is finite equality (4) holds.

Proof. Suppose $N(x)$ is finite $\neq \varnothing$. Let $A=(N(x))^{-1} N(x)$. Then $A$ is finite and, by Lemma 2 (ii)-(iii), $N\left(x^{\sim} * x\right) \subset A$. We have

$$
\begin{aligned}
\left\|\left(x^{\sim} * x\right)^{* n}\right\| & =\sum_{s \in G}\left|\left(x^{\sim} * x\right)^{* n}(s)\right| \\
& =\sum_{s \in A^{n}}\left|\left(x^{\sim} * x\right)^{* n}(s)\right| \leqq\left|A^{n}\right|^{1 / 2}\left(\sum_{s \in A^{n}}\left|\left(x^{\sim} * x\right)^{* n}(s)\right|^{2}\right)^{1 / 2} \\
& =\left|A^{n}\right|^{1 / 2}||\left(x^{\sim} * x\right)^{* n} \|_{2} .
\end{aligned}
$$

Hence, by Lemma 1 , since $T_{x \sim_{* x}}$ is a hermitian operator,

$$
\left\|\left(x^{\sim} * x^{*}\right)^{* n}\right\| \leqq\left|A^{n}\right|^{1 / 2} \lambda\left(\left(x^{\sim} * x\right)^{* n}\right)=\left|A^{n}\right|^{1 / 2}\left(\lambda\left(x^{\sim} * x\right)\right)^{* n} .
$$

Consequently,

$$
\nu\left(x^{\sim} * x\right)=\lim _{n \rightarrow \infty} \|\left(x^{\sim} * x\right)^{* n}||^{1 / n} \leqq \lim _{n \rightarrow \infty} \sup \left|A^{n}\right|^{1 / 2 n} \lambda\left(x^{\sim} * x\right) .
$$

But, since $G$ satisfies $(\mathrm{A}-\mathrm{S})$ and $A \neq \varnothing$,

$$
\lim _{n \rightarrow \infty} \sup \left|A^{n}\right|^{1 / 2 n}=1 \text {, }
$$

whence $\nu\left(x^{\sim} * x\right) \leqq \lambda\left(x^{\sim} * x\right)$, which completes the proof of Theorem 1 . 
COROLLARY 1. If a group $G$ satisfies condition (A-S), then for any $x \in \mathfrak{A}(G)$ such that $N(x)$ is finite $\operatorname{Sp}_{A(G)}\left(x^{\sim} * x\right) \geqq 0$.

Proof. By a standard argument (cf. e.g. [9 pp. 300-301]) we reduce our task to proving that for each $x \in \mathfrak{A}(G)$ with finite support $\left(\delta+x^{\sim} * x\right)^{-1}$ exists. Let $\mathfrak{A}$ be the (commutative) algebra of hermitian elements generated (algebraically) by $\delta$ and $\delta+x^{\sim} * x=y_{0}$. Then, by Lemma 2 (ii)-(iii), for any $y \in A, N(y)$ is finite, whence, since $G$ satisfies (A-S), by Theorem $1, \nu\left(y^{\sim} * y\right)=\lambda\left(y^{\sim} * y\right)$ and, consequently, since $y^{\sim}=y, \nu(y)=\lambda(y)$.

Therefore the completion $\mathfrak{U}^{\nu}$ and $\mathfrak{U}^{\lambda}$ of $\mathfrak{A}$ in the norms $\nu$ and $\lambda$ respectively, are equal. But $\mathfrak{A}^{\lambda}$ is isometrically isomorphic to a Banach *-algebra with the unity of hermitian operators, so $y_{0}^{-1}$ exists in $\mathfrak{Q}^{\lambda}$ and, consequently, $y_{0}^{-1} \in \mathfrak{A}^{\nu}$. This show that in the Gelfand representation of $\mathfrak{U}^{\|\cdot\|}$, the completion of $\mathfrak{U}$ in the norm $\|\cdot\|$, we have

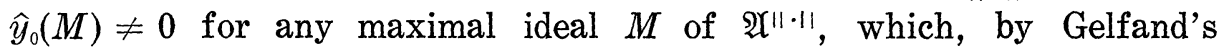
theorem, proves that $y_{0}^{-1} \in \mathfrak{2}\|\cdot\| \subset \mathfrak{A}(G)$, as required.

By virtue of Theorem 1, if $G$ satisfies (A-S), then equality (4) holds for a dense (in the norm $\|\cdot\|$ ) set of hermitian elements $x$ of $\mathfrak{A}(G)$. Clearly the function $\lambda$ is continuous on $\mathfrak{A}(G)$, so if we knew that $\nu$ were continuous, equality (4) would be an immediate consequence of Theorem 1. However, it is known that, in general, for a noncommutative Banach *-algebra the function need not be continuous. The example of S. Kakutani, as presented in [11 p. 282], shows that $\nu$ is not continuous on the algebra of the bounded operators of a Hilbert space. In this case, however, $\nu$ is continuous on hermitian elements. We do not know whether in the case of a nonsymmetric group algebra the function $\nu$ is continuous on hermitian elements.

THEOREM 2. If a group G satisfies condition (C), then equality (4) holds for all elements $x \in \mathfrak{A}(G)$.

Proof. Suppose $G$ satisfies (C) and let $z \in \mathfrak{U}(G)$. For any positive $\varepsilon$ we write

$$
z^{\sim} * z=y+x
$$

where $N(x)=A$ is finite and $\|y\|<\varepsilon$. We are going to prove

$$
\nu\left(z^{\sim} * z\right) \leqq k\|y\|+\lambda(x)
$$

where $k$ is the constant whose existence is postulated by condition (C). Since $\lambda$ is continuous (with respect to the norm $\|\cdot\|$ ), (7) implies 


$$
\nu\left(z^{\sim} * z\right) \leqq \lambda\left(z^{\sim} * z\right)
$$

as desired. To prove (7) we write

$$
\left(z^{\sim} * z\right)^{* n}=(y+x)^{* n}=\sum_{m=0}^{n} \sum_{\sigma, \tau} y^{* p_{1}} * x^{* q_{1}} * \cdots * y^{* p_{r}} * x^{* q_{r}},
$$

where the summation extends over the set $C(m, n)$ of all sequences $\sigma=$ $\left\langle p_{1}, \cdots, p_{r}\right\rangle$ and $\tau=\left\langle q_{1}, \cdots, q_{r}\right\rangle$ of nonnegative integers such that $p_{1}+\cdots+p_{r}=m, q_{1}+\cdots+q_{r}=m-n$. Hence

$$
\left\|\left(z^{\sim} * z\right)^{* n}\right\| \leqq \sum_{m=0}^{n} \sum_{\sigma, \tau}\left\|y^{* p_{1}} * x^{* q_{1}} * \cdots * y^{* p_{r}} * x^{* q_{r}}\right\|
$$

By Lemma 2 (i), we have

$$
\begin{aligned}
& \left\|y^{* p_{1}} * x^{* q_{1}} * \cdots * y^{* p_{r}} * x^{* q_{r}}\right\|=\left\|y^{* p_{1}} * x^{*} q_{1} * \cdots * y^{* p_{r}} * x^{*} q_{r} * \delta\right\| \\
& \quad=\sum_{s \in G}\left|\sum_{\alpha, \beta} y\left(t_{1}\right) \cdots y\left(t_{m}\right) x\left(s_{1}\right) \cdots x\left(s_{n-m}\right) \delta\left(a_{r}^{-1} b_{r}^{-1} \cdots \alpha_{1}^{-1} b_{1}^{-1} s\right)\right|
\end{aligned}
$$

where the summation is all over the set of sequences

$$
\begin{array}{rlrl}
\alpha & =\left\langle t_{1}, \cdots, t_{m}\right\rangle, t_{i} \in G, & & i=1, \cdots, m ; \\
\beta & =\left\langle s_{1}, \cdots, s_{n-m}\right\rangle, s_{i} \in G, & & i=1, \cdots, n-m \\
a_{i}=s_{q_{1}+\cdots+q_{i-1}+1} \cdots s_{q_{1}+\cdots+q_{i}}, & & i=1, \cdots, r, q_{0}=0 \\
b_{i}=t_{p_{1}+\cdots+p_{i-1}+1} \cdots t_{p_{1}+\cdots+p_{i}}, & & i=1, \cdots, r, p_{0}=0 .
\end{array}
$$

Hence

$$
\begin{gathered}
\left\|y^{* p_{1}} * x^{* q_{1}} * \cdots * y^{* p_{r}} * x^{* q_{r}}\right\| \leqq \sum_{s \in G} \sum_{\alpha}\left|y\left(t_{1}\right)\right| \cdots\left|y\left(t_{m}\right)\right| \\
\mid \sum_{\beta} x\left(b_{1}^{-1} s_{1}\right) x\left(s_{2}\right) \cdots x\left(s_{q_{1}}\right) x\left(b_{2}^{-1} s_{q_{1}+1}\right) x\left(s_{q_{1}+2}\right) \cdots x\left(s_{q_{1}+q_{2}}\right) \cdots \\
x\left(b_{r}^{-1} s_{q_{1}+\cdots+q_{r-1}+1}\right) x\left(s_{q_{1}+\cdots+q_{r-1}+2}\right) \cdots x\left(s_{n-m}\right) \delta\left(s_{n-m}^{-1} \cdots s_{1}^{-1} s\right) \mid \\
=\sum_{\alpha}\left|y\left(t_{1}\right)\right| \cdots\left|y\left(t_{m}\right)\right|\left\|x_{b_{1}} * x^{*\left(q_{1}-1\right)} * \cdots * x_{b_{r}} * x^{*\left(q_{r}-1\right)}\right\|,
\end{gathered}
$$

where $x_{b_{i}}(s)=x\left(b_{i}^{-1} s\right), i=1, \cdots, r$. But, since $N(x)=A, N\left(x_{b_{i}}\right)=b_{i} A$, $i=1, \cdots, r$. Hence, by Lemma 2(ii),

$$
N\left(x_{b_{1}} * x^{*\left(q_{1}-1\right)} * \cdots * x_{b_{r}} * x^{*\left(q_{r}-1\right)}\right) \subset b_{1} A A^{\left(q_{1}-1\right)} \cdots b_{r} A A^{\left(q_{r}-1\right)}=b_{1} A^{q_{1}} \cdots b_{r} A^{q_{r}}=P \text {. }
$$

Therefore, by Lemma 1 and Schwarz inequality,

$$
\begin{aligned}
& \left\|x_{b_{1}} * x^{*\left(q_{1}-1\right)} * \cdots * x_{b_{r}} * x_{b_{r}} * x^{*\left(q_{r}-1\right)}\right\| \\
& \quad \leqq|P|^{1 / 2}\left\|x_{b_{1}} * x^{*\left(q_{1}-1\right)} * \cdots * x_{b_{r}} * x^{*\left(q_{r}-1\right)}\right\|_{2} \\
& \quad \leqq|P|^{1 / 2} \lambda\left(x_{b_{1}}\right)(\lambda(x))^{q_{1}-1} \cdots \lambda\left(x_{b_{r}}\right)(\lambda(x))^{q_{r}-1} \\
& \quad=|P|^{1 / 2}(\lambda(x))^{n-m},
\end{aligned}
$$


the last equality being true by virtue of the easily verified fact that $\lambda\left(x_{b}\right)=\lambda(x)$.

On the other hand,

$$
|P| \leqq \sup _{b_{1}, \cdots, b_{r} \in G}\left|b_{1} A^{q_{1}} \cdots b_{r} A^{q_{r}}\right| \leqq \sup \left|t_{1} A t_{2} A \cdots t_{n-m} A\right|
$$

where the least upper bound on the right hand side is taken over all sequences $t(m, n-m)=\left\langle t_{1}, \cdots, t_{n-m}\right\rangle$ with at most $m$ of the $t_{\imath}^{\prime} s$ different from the unity of $G$. Hence, since $G$ satisfies (C),

$$
|P|^{1 / 2} \leqq C(A, c) k^{m} c^{n} \text { for any } c>1 \text {. }
$$

Consequently, by (10) and (9),

$$
\begin{aligned}
& \left\|y^{* p_{1}} * x^{* q_{1}} * \cdots y^{* p_{r}} * x^{*} q_{r}\right\| \\
& \quad \leqq \sum_{a}\left|y\left(t_{1}\right)\right| \cdots\left|y\left(t_{m}\right)\right| k^{m} c^{n} C(\lambda(x))^{n-m} \\
& \quad=c^{n} C k^{m}\|y\|^{m}(\lambda(x))^{n-m} .
\end{aligned}
$$

Therefore, by (8) and (11),

$$
\left\|\left(z^{\sim} * z\right)^{* n}\right\| \leqq f_{A}(n, n) \sum_{m=0}^{n}\left(\begin{array}{l}
n \\
m
\end{array}\right) k^{m}\|y\|^{m}(\lambda(x))^{n-m}=c^{n} C(k\|y\|+\lambda(x))^{n} .
$$

Hence we have

$$
\begin{aligned}
\mathcal{\nu}\left(z^{\sim} * z\right) & =\lim _{n=\infty}\left\|\left(z^{\sim} * z\right)^{* n}\right\|^{1 / n} \\
& \leqq \lim _{n=\infty} \sup c C^{1 / n}(k\|y\|+\lambda(x))=(k\|y\|+\lambda(x)) c .
\end{aligned}
$$

This completes the proof of Theorem 2 .

3. In this section we present some propositions which exhibit some of the classes of groups for which conditions $(\mathrm{A}-\mathrm{S})$ and $(\mathrm{C})$ are satisfied. First we establish some notations:

Let $G$ be a group and let $a, b \in G$. We write

$$
b^{-1} a b=a^{b}, a^{-1} b^{-1} a b=[a, b],\left[\left[a_{1}, \cdots, a_{n-1}\right], a_{n}\right]=\left[a_{1}, \cdots, a_{n}\right] .
$$

If $A, B$ are subsets of $G$,

$$
A^{B}=\left\{a^{b}: a \in A, b \in B\right\} .
$$

REMARK. If $A$ is a subset of $G$, then for $a_{1}, \cdots, a_{n} \in A^{\theta}$ and $b_{1}, \cdots, b_{n} \in G$ we have

$$
a_{1} b_{1} \cdots a_{n} b_{n}=b_{1} \cdots b_{n} a_{1}^{\prime} \cdots a_{n}^{\prime} \text {, where } a_{1}^{\prime}, \cdots, a_{n}^{\prime} \in A^{G} .
$$

(This follows immediately from the fact that $a b=b a^{b}$ for any $a, b \in G$ ). 
Proposition 1. Let $A$ be a finite subset of a group $G$ such that $A=A^{\theta}$. Then $\left|A^{n}\right| \leqq n^{|A|}$.

Proof. If $a_{1}, \cdots, a_{n} \in A$, then

$$
a_{1} \cdots a_{n}=b_{1}^{n_{1}} \cdots b_{k}^{n_{k}}, \quad b_{1}, \cdots, b_{k} \in A
$$

and, moreover, $n_{1}+\cdots+n_{k} \leqq n$ and $k \leqq|A|$. To prove (12) which is, in fact, a version of Dietzmann's Lemma (cf. [8 Vol. II, p. 154]), we suppose that $k$ is minimal with respect to all representations of $a_{1} \cdots a_{n}$ of the form (12). Suppose $k>|A|$. Then there exists at least two elements $b_{i}$ and $b_{j}, 1 \leqq i<j \leqq k$ such that $b_{i}=b_{j}$. Then

$$
b_{1}^{n_{1}} \cdots b_{k}^{n_{k}}=b_{1}^{n_{1}} \cdots b_{i-1}^{n_{i}-1} b_{i}^{n_{i}+n_{j}}\left(b_{l+1}^{c}\right)^{n_{i+1}} \cdots\left(b_{j-1}^{c}\right)^{n_{j-1}} b_{j+1}^{n_{j-1}} \cdots b_{k}^{n_{k}},
$$

where $c=b_{j}^{n_{j}}$, which is a contradiction, since $b_{s}^{c} \in A^{G}=A$. By (12), we have

$\left|A^{n}\right| \leqq$ the number of the sequences $n_{1}, \cdots, n_{k}$

$$
\text { with } \left.\sum_{i} n_{i} \leqq n \text { and } k \leqq|A|\right) \leqq n^{|A|} \text {. }
$$

Definition. A group $G$ is called a FC-group if for any $a \in G$ the set $\{a\}^{G}$ is finite. (cf. e.g. [8 Vol. II, pp. 154 and 269]).

Proposition 2. If $G$ is a FC-group, then it satisfies (C) with constant $k=1$.

In fact, let $A$ be a finite subset of $G$. Since $G$ is FC-group, the set $B=A^{G}$ is finite. Hence

$$
\left|t_{1} A t_{2} A \cdots t_{n} A\right| \leqq\left|A^{t_{2} t_{3} \cdots t_{n}} A^{t_{3} \cdots t_{n}} \cdots A^{t_{n}}\right| \leqq\left|B^{n}\right| \leqq n^{|B|}=o\left(c^{n}\right)
$$

for any $c>1$.

Proposition 3. If $F$ is a group which contains a subgroup $G$ of finite index in $F$ such that $G$ is a FC-group, then $F$ satisfies (C).

Proof. We show first that if $M$ it a finite subset of $G$, then the set $M^{F}$ is finite. Let $M_{0}=M^{\theta}$. Since $G$ is FC-group, $M_{0}$ is finite. Denote by $\phi$ the function which selects one element $\phi(f)$ out of each of the cosets $G f, f \in F$, and let $\phi(G)=1$ - the unit element of $F$. Let

$$
\dot{\phi}(F)=H=\left\{h_{1}, \cdots, h_{k}\right\} .
$$

We have

$$
M^{F}=M_{1}=\bigcup_{f \in F} M_{0}^{\phi(f)} .
$$


In fact, if $s, f \in F$, there exists a $g \in G$ such that

$$
\phi(f) s=g \phi(\phi(f) s)=g \phi(f s) .
$$

Hence

$$
M_{1}^{s}=\bigcup_{f \in F} M_{0}^{\phi(f) s}=\bigcup_{f \in F} M_{0}^{g \phi(f s)}=\bigcup_{f \in F} M_{0}^{\phi(f)}=M_{1} .
$$

Thus, since $\phi(F)$ is finite, $M^{F}$ is finite.

Now, let

$$
Q=\left\{h_{i} h_{j}\left(\phi\left(h_{i} h_{j}\right)\right)^{-1}: i, j=1, \cdots, k\right\} .
$$

Clearly, $Q$ is finite and $Q \subset G$. By virtue of what we have proved above, $Q^{F}=Q_{1}$ is finite. We now prove that for any sequence $u_{1}, \cdots, u_{n}$ with $u_{i} \in\{1, \cdots, k\}, i=1, \cdots, n$, we have

$$
h_{u_{1}} \cdots h_{u_{n}} \in Q^{n} H \subset Q_{1}^{n} H=H Q_{1}^{n} .
$$

Let $f_{0}=1, f_{i}=h_{u_{1}} \cdots h_{u_{i}}, i=1, \cdots, n$, and let $a_{i}=\phi\left(f_{i}\right)$. Then

$$
f_{n} a_{n}^{-1}=a_{0} h_{u_{1}} a_{1}^{-1} a_{1} h_{u_{2}} a_{2}^{-1} a_{2} \cdots a_{n-1}^{-1} a_{n-1} h_{u_{n}} a_{n}^{-1} \text {. }
$$

But for any $i=1, \cdots, n$,

$$
a_{i}=\phi\left(f_{i}\right)=\phi\left(f_{i-1} h_{u_{i}}\right)=\phi\left(\phi \left(f_{i-\mathrm{I}}\left(h_{u_{i}}\right)=\phi\left(a_{i-1} h_{u_{i}}\right) .\right.\right.
$$

Hence

$$
f_{n} a_{n}^{-1}=a_{0} h_{u_{1}}\left(\phi\left(a_{0} h_{u_{1}}\right)\right)^{-1} \cdots a_{n-1} h_{u_{n}}\left(\phi\left(a_{n-1} h_{u_{n}}\right)\right)^{-1} \in Q^{n} .
$$

and, consequently,

$$
h_{u_{1}} \cdots h_{u_{n}}=f_{n} \in Q^{n} a_{n} \subset Q^{n} H,
$$

which completes the proof of (13).

Now let $A$ be a finite subset of $F$. There exists a finite set $M \subset G$ such that $A \subset H M$. Consider the finite set

$$
B=H M^{F} \text {. }
$$

Clearly, $A \subset B$. For every two nonnegative integers $m \leqq n$, let $t(m, n)$ be as in Section 1. We have

$$
\left|t_{1} B \cdots t_{n} B\right|=\left|(B \cdots B)^{s_{1}}(B \cdots B)^{s_{2}} \cdots(B \cdots B)^{s_{m+1}}\right|,
$$

where $\left\langle t_{1}, \cdots, t_{n}\right\rangle=t(m, n), t_{j_{1}}, \cdots, t_{j_{m}}$ are the $t_{j}^{\prime} s$ different from the unity of $F$, for every $i=1, \cdots, m s_{i}=t_{j_{i}} \cdots t_{j_{m}}$ and $s_{m+1}=1$.

Each element of the set on the right hand side of (14) is of the form

$$
f=\left(h_{1} g_{1} \cdots h_{r_{1}} g_{r_{1}}\right)^{s_{1}} \cdots\left(h_{r_{m}+1} g_{r_{m}+1} \cdots h_{r_{m+1}} g_{r_{m+1}}\right)^{s_{m+1}},
$$


where $g_{i} \in M^{F}, i=1, \cdots, n$. Then

$$
f=\left(h_{1} \cdots h_{r_{1}}\right)^{s_{1}} \cdots\left(h_{r_{m}+1} \cdots h_{r_{m+1}}\right)^{s_{m+1}} g_{1}^{\prime} \cdots g_{n}^{\prime},
$$

where $g_{i}^{\prime} \in M^{F}, i=1, \cdots, n$. But, by (13), for any $i=1, \cdots, m+1$ we have

$$
h_{r_{i-1}} \cdots h_{r_{i}}=h_{i}^{\prime} q_{i}, \quad \text { where } \quad h_{i}^{\prime} \in H \quad \text { and } \quad q_{i} \in Q^{\left(r_{i}-r_{i-1}\right)} .
$$

Consequently, since $Q_{1}^{F}=Q_{1}$,

$$
f=h_{1}^{s_{1}} \cdots h_{m+1}^{s_{m+1}} q_{1}^{\prime} \cdots q_{m+1}^{\prime} g_{1}^{\prime} \cdots g_{n}^{\prime}
$$

and so, since

$$
\begin{gathered}
\sum_{i=1}^{m+1}\left(r_{i}-r_{i-1}\right)=n, \\
f \in H^{s_{1}} \cdots H^{s_{m+1}} Q_{1}^{n} M_{1}^{n} .
\end{gathered}
$$

Therefore, since $\left|H^{s}\right|=|H|$ for any $s \in F$, and $|H|=k$,

$$
\left|t_{1} B \cdots t_{n} B\right| \leqq\left|H^{s_{1}}\right| \cdots\left|H^{s_{m+1}}\right|\left|Q_{1}^{n}\right|\left|M_{1}^{n}\right| \leqq|H|^{m}|H| n^{\left(\left|Q_{1}\right|+\left|M_{1}\right|\right)},
$$

whence, since $|H| n^{\left(\left|Q_{1}\right|+\left|M_{1}\right|\right)}=o\left(c^{n}\right)$, Proposition 3 follows.

COROLLARY 2. If a group G contains a FC-group as a subgroup of finite index, then equality (4) holds for any element $x$ of the group algebra $A(G)$ of $G$ and, consequently, $A(G)$ is symmetric.

Proposition 4. The direct product of finitely many groups which satisfy (C) satisfies (C). $(\mathrm{A}-\mathrm{S})$.

Proposition 5. If $G$ is a locally nilpotent group, then $G$ satisfies

This follows from the fact that if $A=\left\{a_{1}, \cdots, a_{k}\right\}$ is a finite subset of $G, H$ is the subgroup generated by $A$, which, by assumption, is nilpotent of class, say, $s$, then any element of $A^{n} \subset H$ is of the form

$$
\prod_{\imath=1}^{k} a_{i}^{n(i)} \prod_{i_{1}, i_{2}=1}^{k}\left[a_{i_{1}}, a_{i_{2}}\right]^{n\left(i_{1}, i_{2}\right)} \cdots \prod_{i_{1}, \cdots l_{s}=1}^{k}\left[a_{i_{1}}, \cdots, a_{i_{s}}\right]^{n\left(i_{1}, \cdots, i_{s}\right)}
$$

where $n\left(i_{1}, \cdots, i_{j}\right)$ are nonnegative integers $\leqq f_{j}(n), j=1, \cdots, s$, and $f_{j}(n)$ is an integral valued polynomial. (The exact from of $f_{j}(n)$ can be easily established by the use of the collecting process as described in [6] and [5] but it is irrelevant to us here.) Thus

$$
\left|A^{n}\right| \leqq\left(f_{1}(n)\right)^{k^{1}} \cdots\left(f_{s}(n)\right)^{k^{s}}=o\left(c^{n}\right) \text { for any } c>1 \text {. }
$$

Proposition 6. Condition (C) is not satisfied by nilpotent groups, in general. 
Proposition 7. Condition (A-S) is not satisfied by soluble groups, in general.

\section{REFERENCES}

1. G. M. Adel 'son-Vel' skit and Yu. A. Šreider, The Banach mean on groups, Uspehi Mat. Nauk (N.S.) 12 (1957), 131-136.

2. Robert A. Bonic, Symmetry in group algebras of discrete groups, Pacific J. Math. 11 (1961), 73-94.

3. J. M. G. Fell, The dual spaces of $C^{*}$-algebras, Trans. Amer. Math. Soc. 94 (1960), 365-403.

4. E. F $\phi$ lner, On groups with full Banach mean value, Math. Scand., 3 (1955), 243-254.

5. Marschall Hall, Jr., The theory of groups, The Macmillan Company, 1959.

6. Philip Hall, A contribution to the theory of groups of prime power order, Proc. London Math. Soc. 36 (1933), 29-95.

7. A. Hulanicki, Groups whose regular representation weakly contains all unitary representations, Studia Math. 24 (1964), 37-59.

8. A. G. Kurosh, The theory of group, Chelsea Publishing Company, (1956).

9. M. A. Naimark, Normed rings, P. Noordhoff, Ltd., Groningen, (1960).

10. D. Raikov, On the theory of normed rings with involution, Dokklady Akad. Nauk SSSR 54 (1949), 387-390 (Russian).

11. Charles E. Rickart, General theory of Banach algebras, D. Van Nostrand Company, (1960).

Received January 10, 1965.

Institute of Mathematics, Polish Akademy of Sciences

and

The UNIVERSity OF WASHINGTON 



\section{PACIFIC JOURNAL OF MATHEMATICS}

\section{EDITORS}

H. SAMELSON

Stanford University

Stanford, California

R. M. BLUMENTHAL

University of Washington

Seattle, Washington 98105

\section{*J. DugundJI}

University of Southern California Los Angeles, California 90007

RICHARD ARENS

University of California

Los Angeles, California 90024

\section{ASSOCIATE EDITORS}

E. F. BECKENBACH
F. WOLF

K. YosIDA

\section{SUPPORTING INSTITUTIONS}

\author{
UNIVERSITY OF BRITISH COLUMBIA \\ CALIFORNIA INSTITUTE OF TECHNOLOGY \\ UNIVERSITY OF CALIFORNIA \\ MONTANA STATE UNIVERSITY \\ UNIVERSITY OF NEVADA \\ NEW MEXICO STATE UNIVERSITY \\ OREGON STATE UNIVERSITY \\ UNIVERSITY OF OREGON \\ OSAKA UNIVERSITY \\ UNIVERSITY OF SOUTHERN CALIFORNIA
}

\author{
STANFORD UNIVERSITY \\ UNIVERSITY OF TOKYO \\ UNIVERSITY OF UTAH \\ WASHINGTON STATE UNIVERSITY \\ UNIVERSITY OF WASHINGTON \\ AMERICAN MATHEMATICAL SOCIETY \\ CHEVRON RESEARCH CORPORATION \\ TRW SYSTEMS \\ NAVAL ORDNANCE TEST STATION
}

Mathematical papers intended for publication in the Pacific Journal of Mathematics should be typewritten (double spaced). The first paragraph or two must be capable of being used separately as a synopsis of the entire paper. It should not contain references to the bibliography. Manuscripts may be sent to any one of the four editors. All other communications to the editors should be addressed to the managing editor, Richard Arens at the University of California, Los Angeles, California 90024 .

50 reprints per author of each article are furnished free of charge; additional copies may be obtained at cost in multiples of 50 .

The Pacific Journal of Mathematics is published monthly. Effective with Volume 16 the price per volume (3 numbers) is $\$ 8.00$; single issues, $\$ 3.00$. Special price for current issues to individual faculty members of supporting institutions and to individual members of the American Mathematical Society: $\$ 4.00$ per volume; single issues $\$ 1.50$. Back numbers are available.

Subscriptions, orders for back numbers, and changes of address should be sent to Pacific Journal of Mathematics, 103 Highland Boulevard, Berkeley 8, California.

Printed at Kokusai Bunken Insatsusha (International Academic Printing Co., Ltd.), No. 6, 2-chome, Fujimi-cho, Chiyoda-ku, Tokyo, Japan.

PUBLISHED BY PACIFIC JOURNAL OF MATHEMATICS, A NON-PROFIT CORPORATION

The Supporting Institutions listed above contribute to the cost of publication of this Journal, but they are not owners or publishers and have no responsibility for its content or policies.

* Paul A. White, Acting Editor until J. Dugundji returns. 


\section{Pacific Journal of Mathematics}

\section{Vol. 18, No. 2 \\ April, 1966}

Alexander V. Arhangelskii, On closed mappings, bicompact spaces, and a problem of P. Aleksandrov .............................. 201

A. K. Austin, A note on loops . . . . . . . . . . . . . . . . . . . . . . . . . . . . 209

Lawrence Peter Belluce and William A. Kirk, Fixed-point theorems for families of contraction mappings...................... 213

Luther Elic Claborn, Every abelian group is a class group ............ 219

Luther Elic Claborn, A note on the class group .................. 223

Robert Stephen De Zur, Point-determining homomorphisms on multiplicative semi-groups of continuous functions............. 227

Raymond William Freese, A convexity property ................ 237

Frederick Paul Greenleaf, Characterization of group algebras in terms of their translation operators ......................... 243

Andrzej Hulanicki, On the spectral radius of hermitian elements in group algebras....................................... 277

Michael Bahir Maschler and Bezalel Peleg, A characterization, existence proof and dimension bounds for the kernel of a game ............ 289

Yiannis (John) Nicolas Moschovakis, Many-one degrees of the predicates

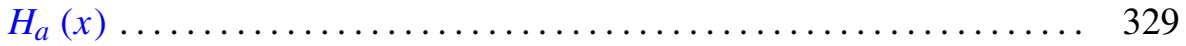

G. O. Okikiolu, $n$th order integral operators associated with Hilbert transforms.

C. E. Rickart, Analytic phenomena in general function algebras ... 361

K. N. Srivastava, On an entire function of an entire function defined by Dirichlet series

Paul Elvis Waltman, Oscillation criteria for third order nonlinear differential equations .......................... 